\title{
Unsatisfactory glycemic control in type 2 Diabetes mellitus patients: predictive factors and negative clinical outcomes with the use of antidiabetic drugs
}

\author{
Maria Aparecida Marczynski ${ }^{1}$, Karine Laura Cortellazzi ${ }^{2}$, Sílvio Barberato-Filho ${ }^{1}$, Rogério Heládio \\ Lopes Motta ${ }^{3}$, Alexandre Eduardo Franzin Vieira ${ }^{4}$, Maria Teresa Verrone Quilici ${ }^{4}$, Cristiane de \\ Cássia Bergamaschi ${ }^{1^{*}}$
}

\begin{abstract}
${ }^{1}$ Department of Pharmaceutical Sciences, University of Sorocaba, Sorocaba, Brazil, ${ }^{2}$ Department of Social Dentistry, Dental School of Piracicaba, State University of Campinas, Piracicaba, Brazil, ${ }^{3}$ Department of Pharmacology, Anesthesiology and Therapeutics Dental School and Research Center, São Leopoldo Mandic, Brazil, ${ }^{4}$ Sorocaba Medical School, Pontifical

Catholic University, Sorocaba, Brazil
\end{abstract}

\begin{abstract}
Many factors can interfere with glycemic control in patients with type 2 diabetes mellitus and this patient group has an increased risk of experiencing drug-related negative outcomes (DNO). The aim of this study was to identify the predictive factors of unsatisfactory glycemic control and DNO in this group of patients. A cross-sectional study was conducted collecting data from prescriptions and interviews with 100 patients of the Endocrinology Clinic of the Hospital Complex of Sorocaba, São Paulo, Brazil. Variables associated with unsatisfactory glycemic control were determined and the DNO associated with antidiabetic drugs identified. Age ( $<65$ years) $(\mathrm{OR}=4.09)$, family history of diabetes $(\mathrm{OR}=3.24)$, use of combined therapy to treat diabetes $(2-4$ antidiabetic drugs) $(\mathrm{OR}=5.13)$ and presence of $\mathrm{DNO}$ $(\mathrm{OR}=5.92)$ were found to be predictive factors for poor patient glycemic control. DNO were observed in $49 \%$ of the patients and were caused predominantly by ineffectiveness in patients with poor glycemic control $(p<0.05)$. There was no significant difference between groups (satisfactory and unsatisfactory glycemic control) for DNO caused by safety issues ( $p>0.05$ ). Characterization of the profile of patients with uncontrolled diabetes and of aspects associated with drug treatment can contribute to the planning of interventions to improve patient care.
\end{abstract}

Uniterms: Type 2 Diabetes mellitus. Type 2 Diabetes mellitus/study/drugs use. Pharmaceutical care. Drug-related negative outcomes.

\section{INTRODUCTION}

Diabetes mellitus requires constant care and has reached high epidemiological levels. In 2013, the disease affected 11.9 million Brazilians over 18 years, ranking Brazil fourth in the world for number of people with diabetes (Almeida-Pititto, 2015). The disease affects $17.1 \%$ of Brazilians aged $55-64$ years and $22.1 \%$ of individuals over 65 years of age (Vigitel, 2012). Globally, prevalence among adults aged 20-79 was $8.3 \%$ (366.2 million people) in 2011, a rate set to rise to an estimated

*Correspondence: C. C. Bergamaschi. Universidade de Sorocaba, UNISO. Rodovia Raposo Tavares, Km 92.5 - 18023-000 - Sorocaba, SP, Brasil. Phone/ Fax: 152101 7104. E-mail: cristiane.motta@prof.uniso.br
$9.9 \%$ by 2030 , affecting approximately 552 million people (Whiting et al., 2011).

Due to the population's growing longevity its accompanying demand for greater health care, diabetes represents a challenge for public health care (Trimeche et al., 2013). Thus, strategies to reduce multifactorial risks and favor glycemic control are necessary (American Diabetes Association, 2014). The aim of treatment is to reduce morbidity and mortality related to the disease, where changes in lifestyle are recommended along with rational drug use and education for self-care (Correr et al., 2011).

Expert groups have produced several guidelines and the American Diabetes Association (ADA) guideline is generally accepted by the World Health Organization (WHO) and recommended by the Brazilian Diabetes 
Association. These guidelines recommend glycated hemoglobin $(\mathrm{HbA} 1 \mathrm{c})$ levels lower than $7 \%$ for adults and up to $8 \%$ for the elderly for adequate glycemic control. HbA1c levels for the elderly take into account the increased risk of hypoglycemia, extensive comorbidities, and reduced life expectancy (Wallia, Molitch, 2014).

Glycemic control in type 2 diabetes mellitus prevents or reduces disease-related complications and is essential for controlling the intended glycemic targets (Saenz et al., 2005; Nathan et al., 2009; Duckworth et al., 2009). However, lack of adherence to treatment (Donnan et al., 2002), cognitive dysfunctions (Grober et al., 2011), inappropriate eating habits, a sedentary lifestyle and overweight/obesity (Nathan et al., 2009), among other factors, have been shown to negatively influence the desired therapeutic goals.

According to the literature, there is a high prevalence of drug-related problems (DRP) in diabetes mellitus patients (Von Rozendaal, Krass, 2009), mainly due to polypharmacy and high number of comorbidities (Zaman, Chai, 2013).

Pharmacotherapy follow-up is a clinical practice in which the pharmacist is responsible for the patient's needs regarding the drug, through the detection, resolution, and prevention of drug-related negative outcomes (DNO). The Dader method for pharmacotherapy follow-up defines DRP as situations that hinder pharmacotherapy aims and may or may not result in DNO, which are considered inadequate for patient health and associated with the use or lack of use of drugs (Committee of Consensus, 2007). This classification has been used in the literature by several authors (Zaman, Chai, 2013; Takahashi et al., 2011; Gastelurrutia et al., 2011; Amariles et al., 2012).

The results of the present study can contribute to the creation of strategies that favor patient glycemic control by helping to identify the factors associated with unsatisfactory glycemic control of type 2 diabetes mellitus in patients as well as describing the drug treatment profile by identifying antidiabetic drug-related negative clinical outcomes. The aim of the study was to identify the predictive factors of unsatisfactory glycemic control and antidiabetic drug-related negative outcomes in type 2 diabetes mellitus patients.

\section{MATERIAL AND METHODS}

\section{Ethical aspects}

The study was approved by the Joint Ethics Research Committee of Sorocaba University - CEP-UNISO (Protocol 879,747).

\section{Study design}

A cross-sectional, analytical study was conducted.

\section{Study population}

All type 2 diabetes mellitus patients $(n=197)$ scheduled for a medical appointment at the Endocrinology Clinic of the Hospital Complex of Sorocaba, São Paulo State, Brazil, between August 2013 and August 2014 were asked to participate in the study.

The patients were divided into 2 groups according to $\mathrm{HbA1c}$ test results: satisfactory and unsatisfactory glycemic control. Unsatisfactory glycemic control was defined as $\mathrm{HbA} 1 \mathrm{c} \geq 7 \%$ in adults and $>8 \%$ in elderly (American Diabetes Association, 2014; Brazilian Society of Diabetes, 2014).

\section{Eligibility criteria}

Individuals aged 18 or older with a positive diagnosis for type 2 diabetes mellitus for at least 6 months were included in the study. Individuals that did not have glycemic levels confirmed by the HbAlc test within the 4 weeks leading up to the interview or that could not provide the necessary data for the study were excluded.

\section{Data collection}

Pharmacists were invited by the physicians responsible for the Endocrinology Department (at the Conjunto Hospitalar de Sorocaba) to provide their services. After medical consultation, all the patients were taken by physicians to the pharmaceutical interview room. Patients that agreed to take part in this study formalized their acceptance by signing an informed consent form. Patients' data were collected during the interview with the pharmacists, as well as from their respective medical prescriptions and medical records. During the interview, information about health problems (diagnosed or otherwise) and drugs used by patients was collected in order to check whether the drug treatment was appropriate in terms of indication, effectiveness and safety.

Sociodemographic and clinical variables (independent variables) associated with unsatisfactory patient glycemic control (dependent variable) were determined. Demographic variables (gender, age, housing, education, and average income) were obtained during the interview. Clinical variables (family history of diabetes, time since diagnosis, presence of complications due to diabetes, presence of comorbidities, obesity, use of insulin, 
hypoglycemic crises, and polypharmacy) were obtained during the interview and also from medical records and prescriptions. Polypharmacy was defined as the use of three or more drugs (Noia et al., 2012).

The information allowing identification of the DNO was collected during the interview. Patients that had DNO were informed about the results and invited to participate in the pharmacotherapy follow-up program.

The Dader method was used by the pharmacists to identify DRP and DNO according to the Third Consensus of Granada (Committee of Consensus, 2007). These were divided into three categories and six subcategories: 1) need (patient suffers from a health problem associated with not using the necessary drug or patient suffers from a health problem associated with using an unnecessary drug); 2 ) effectiveness (patient suffers from a health problem associated with non-quantitative ineffectiveness of the drug and patient suffers from a health problem associated with quantitative ineffectiveness); and 3) safety (patient suffers from a health problem associated with nonquantitative safety or patient suffers from a health problem associated with quantitative safety).

Noncompliance with treatment was also established according to the Dader method, i.e., it may occur due to a problem of necessity (the patient does not use the drug or uses it inappropriately).

Standard product information from the Brazilian National Surveillance Agency and Drugdex ${ }^{\circledR}$ System (Klasco, 2013) was used in order to verify data regarding dosage, frequency, period of treatment, adverse effect, contraindications, and precaution with use and drug interactions.

Drug interactions, and causality and severity of adverse effects were obtained by consensus among the pharmacists and, when necessary, the physicians attending the patients were also involved. Drug interactions were classified as severe (when threatening a patient's life; it may or may not require medical intervention in order to prevent or minimize adverse effects), contraindicated (when it absolutely precludes the use of concomitant drugs) and moderate (when it may exacerbate patient's health condition and/or requires changes in treatment) according to Klasco (2013). Drug interaction was considered when the result of this interaction was possibly associated with the clinical condition of the patient. Weak interactions were not considered.

The Naranjo algorithm established the causality of the adverse effect as definite, probable, possible, or doubtful (Naranjo et al., 1981). Possible causes for adverse effects were considered when classified as definite (clinical situation that occurs in a reasonable period relative to the time drug has been administrated; it cannot be explained by the existing disease or another drug and/or chemical and is confirmed when the reaction disappears as the drug is suspended, but returns as drug is administrated again) and probable (as per the previously described criteria, but it is not necessary to reintroduce the drug). Regarding severity, the adverse effects were classified as lethal (contribute to patient's death), severe (need to discontinue treatment and introduce specific treatment, leading to hospitalization or extended hospitalization), moderate (no need to interrupt and/or change treatment, but may need therapeutic changes and to extend hospitalization) or mild (no need to suspend pharmacotherapy or for specific treatment and/or antidotes) (Edwards, Aronson, 2000).

\section{Statistical analysis}

Bivariate analyses using the Chi-square test $(\chi 2)$ or Fisher's exact test was performed to test the influence of independent variables on the dependent variable. After this multiple logistic regression analyses, the stepwise procedure was performed in order to identify the risk indicators for unsatisfactory glycemic control. Only the independent variables with a $p$-value of less than 0.20 were tested in the regression analysis in order to eliminate those that would make little contribution to the model, where those with $p \leq 0.05$ remained in model after adjustments. The logistic regression models were adjusted estimating the Odds Ratios (OR), their 95\% confidence intervals (CI), and significance levels. Statistical tests were performed using the SAS software program (SAS institute Inc. 2010, version 9.3, Cary, North-Carolina/USA) and Bioestat 5.3. The significance level was $5 \%$.

\section{RESULTS}

Of the 197 patients asked to participate in the study, 103 agreed to take part but $3(2.9 \%)$ were not eligible for the study because they did not have a glycated hemoglobin test. Sociodemographic and clinical variables are shown in Table I. The Chi-square test revealed a significant association between unsatisfactory glycemic control and age, family history for diabetes, obesity, insulin use, monotherapy or combination therapy for diabetes treatment, and DNO presence $(\mathrm{p} \leq 0.05)$.

On the multiple logistic regression analysis, individuals aged under $65(\mathrm{OR}=4.09)$, with a family history for diabetes $(\mathrm{OR}=3.24)$, using combined therapy for diabetes treatment $(\mathrm{OR}=5.13)$, and having antidiabetic drug-related negative outcomes $(\mathrm{OR}=5.92)$, had a greater likelihood of unsatisfactory glycemic control (Table I). 
TABLE I - Sociodemographic and clinical variables associated with glycemic control in type 2 Diabetes mellitus patients

\begin{tabular}{|c|c|c|c|c|c|c|}
\hline Variables & $\begin{array}{l}\text { Satisfactory } \\
\quad(\mathbf{n}=43) \\
\text { n }(\%)\end{array}$ & $\begin{array}{c}\text { Unsatisfactory } \\
\begin{array}{c}(\mathbf{n}=\mathbf{5 7}) \\
\mathbf{n}(\%)\end{array}\end{array}$ & $\begin{array}{c}\text { Bivariate analysis } \\
\text { Crude OR } \\
(95 \% \mathrm{CI})\end{array}$ & p-value & $\begin{array}{c}\text { Multiple } \\
\text { Analysis } \\
\text { Adjusted OR } \\
(\mathbf{9 5 \% C I )} \\
\end{array}$ & p-value \\
\hline \multicolumn{7}{|l|}{ Gender } \\
\hline Female & $26(41.27)$ & $37(58.73)$ & Ref & & & \\
\hline Male & $17(45.95)$ & $20(54.05)$ & $0.83(0.36-1.87)$ & 0.6484 & & \\
\hline \multicolumn{7}{|l|}{ Age (years) } \\
\hline$<65$ & $15(29.41)$ & $36(70.59)$ & $3.20(1.40-7.31)$ & 0.0051 & $4.09(1.46-11.41)$ & $* 0.0071$ \\
\hline$\geq 65$ & $28(57.14)$ & $21(42.86)$ & ref & & ref & \\
\hline$* *$ Mean age & $65.93 \pm 10.66$ & $59.63 \pm 13.55$ & & & & \\
\hline \multicolumn{7}{|l|}{ Housing } \\
\hline Resides alone & $5(29.41)$ & $12(70.59)$ & $2.02(0.65-6.26)$ & 0.2142 & & \\
\hline Resides with family & $38(45.78)$ & $45(54.22)$ & ref & & & \\
\hline \multicolumn{7}{|l|}{ Education (years) } \\
\hline$\leq 4$ & $5(29.41)$ & $12(70.59)$ & ref & & & \\
\hline$>4$ & $38(45.78)$ & $45(54.22)$ & $0.49(0.15-1.52)$ & 0.2142 & & \\
\hline \multicolumn{7}{|l|}{ Monthly Income } \\
\hline$\leq 1$ minimum wage & $23(43.40)$ & $30(56.60)$ & ref & & & \\
\hline$>1$ minimum wage & $20(42.55)$ & $27(57.45)$ & $1.03(0.46-2.28)$ & 0.9323 & & \\
\hline \multicolumn{7}{|l|}{ Family history } \\
\hline No & $15(60.00)$ & $10(40.00)$ & ref & & ref & \\
\hline Yes & $28(37.33)$ & 47 (62.67) & $2.56(1.00-6.60)$ & 0.0474 & $3.24(0.96-10.96)$ & $* 0.0059$ \\
\hline \multicolumn{7}{|c|}{ Time since diagnosis (years) } \\
\hline$\leq 10$ & $17(51.52)$ & $16(48.48)$ & $0.59(0.25-1.38)$ & 0.2274 & & \\
\hline$>10$ & $26(38.81)$ & $41(61.19)$ & ref & & & \\
\hline \multicolumn{7}{|l|}{ Diabetes complications } \\
\hline No & $27(47.37)$ & $30(52.63)$ & $0.65(0.29-1.47)$ & 0.3097 & & \\
\hline Yes & $16(37.21)$ & $27(62.79)$ & ref & & & \\
\hline \multicolumn{7}{|c|}{ Number of comorbidities } \\
\hline $0-2$ & $24(41.38)$ & $34(58.62)$ & $1.17(0.52-2.60)$ & 0.7005 & & \\
\hline $3-6$ & $19(45.24)$ & $23(54.76)$ & ref & & & \\
\hline \multicolumn{7}{|c|}{ Obesity (BMI > 30 kg/m²) } \\
\hline No & $38(48.10)$ & $41(51.90)$ & $0.33(0.11-1.00)$ & 0.0457 & & \\
\hline Yes & $5(23.81)$ & $16(76.19)$ & ref & & & \\
\hline \multicolumn{7}{|l|}{ Hypoglycemia } \\
\hline No & $15(35.71)$ & $27(64.29)$ & $1.68(0.74-3.79)$ & 0.2105 & & \\
\hline Yes & $28(48.28)$ & $30(51.72)$ & ref & & & \\
\hline
\end{tabular}


TABLE I - Sociodemographic and clinical variables associated with glycemic control in type 2 Diabetes mellitus patients (cont.)

\begin{tabular}{|c|c|c|c|c|c|c|}
\hline Variables & $\begin{array}{l}\text { Satisfactory } \\
\quad(\mathbf{n}=43) \\
\text { n }(\%)\end{array}$ & $\begin{array}{l}\text { Unsatisfactory } \\
\qquad \begin{array}{c}(\mathbf{n}=\mathbf{5 7}) \\
\mathbf{n}(\%)\end{array}\end{array}$ & $\begin{array}{c}\text { Bivariate analysis } \\
\text { Crude OR } \\
(95 \% \mathrm{CI})\end{array}$ & p-value & $\begin{array}{c}\text { Multiple } \\
\text { Analysis } \\
\text { Adjusted OR } \\
(95 \% \mathrm{CI})\end{array}$ & p-value \\
\hline \multicolumn{7}{|l|}{ In use of insulin } \\
\hline No & $22(55.00)$ & $18(45.00)$ & $0.44(0.19-0.99)$ & 0.0478 & & \\
\hline Yes & $21(35.00)$ & $39(65.00)$ & ref & & & \\
\hline \multicolumn{7}{|l|}{ Drug for diabetes } \\
\hline Monotherapy & $22(73.33)$ & $8(36.67)$ & ref & & ref & \\
\hline Association & $21(30.00)$ & $49(70.00)$ & $4.38(1.80-10.65)$ & 0.0008 & $5.13(1.69-15.51)$ & $* 0.0038$ \\
\hline \multicolumn{7}{|l|}{ Polypharmacy } \\
\hline No & $3(42.86)$ & $4(57.14)$ & ref & & & \\
\hline Yes & $40(43.01)$ & $53(56.99)$ & $0.99(0.21-4.69)$ & 0.4567 & & \\
\hline \multicolumn{7}{|c|}{ *Presence of DNO } \\
\hline No & $33(66.00)$ & $17(34.00)$ & ref & & & \\
\hline Yes & $10(20.00)$ & $40(80.00)$ & $7.76(3.13-19.23)$ & 0.0001 & $5.92(2.15-16.31)$ & $* 0.0006$ \\
\hline
\end{tabular}

No differences were observed between the groups for drugs used ( $p>0.05)$, which were metformin and NPH insulin, the most commonly prescribed. Monotherapy was more common in the satisfactory glycemic control group $(\mathrm{p} \leq 0.05)$. The combination of two antidiabetic agents predominated in the uncontrolled diabetes group $(\mathrm{p} \leq 0.05)$. For treatment regimens, the most prescribed for the satisfactory glycemic control group were monotherapy with metformin $(\mathrm{p} \leq 0.05)$ and the combination of metformin with NPH insulin ( $p>0.05)$. In the unsatisfactory glycemic control group, combinations of metformin and sulfonylureas and metformin with NPH insulin were the most prescribed (Table II).

Forty-nine patients $(49.0 \%)$ had antidiabetic drugrelated negative outcomes, and $114 \mathrm{DNO}$ were observed (average of $2.27+1.26 \mathrm{DNO} /$ patient). No negative outcomes were found related to the need for drug use. A difference was detected regarding the quantitative ineffectiveness DNO due to non-compliance with daily dose $(p \leq 0.05)$. The negative outcomes related to safety in the use of antidiabetic agents were mainly non-quantitative safety due to adverse effects and drug interactions $(p>0.05)$. The number of ineffectiveness and safety DNO was higher in the uncontrolled diabetes group $(p \leq 0.05)$ (Table III).
Table IV shows drug interactions possibly associated with DNO. Thirteen drug interactions associated with non-quantitative ineffectiveness were observed in the unsatisfactory glycemic control group, with a consequent risk of hyperglycemia. Drug interactions and precautions in use associated with non-quantitative and quantitative safety, respectively, were mainly associated with the risk of hypoglycemia. Five patients suffering from renal disease had quantitative unsafety $\mathrm{DNO}$ also related to the risk of hypoglycemia due to insulin use in the presence of the disease, which required dose adjustment. Overall, 22 patients reported having presented hypoglycemic crises.

Adverse effects were mainly related to the use of metformin where the most frequent effects included nausea, diarrhea, heartburn, and abdominal pain for both groups. These effects were categorized as definite and probable and having mild-to-moderate severity (Table V).

\section{DISCUSSION}

Diabetes is a high epidemiological chronic disease whose therapeutic goal is to maintain the glycemic control to prevent and/or postpone the related complications in order to provide benefits to the patients (Duckworth et al., 2009; Holman et al., 2014). Therefore, knowing the factors 
TABLE II - Frequency of drugs prescribed for type 2 Diabetes mellitus according to glycemic control

\begin{tabular}{|c|c|c|c|}
\hline & Satisfactory & Unsatisfactory & p-value \\
\hline Glycated hemoglobin (\%) & mean $\pm \mathbf{S D}$ & mean $\pm \mathbf{S D}$ & \\
\hline Adults & $6.7 \pm 0.47$ & $8.9 \pm 1.41$ & $* 0.0001$ \\
\hline Elderly & $7.2 \pm 0.80$ & $9.4 \pm 0.83$ & $* 0.0001$ \\
\hline Drugs (ATC) & n (\%) & n $(\%)$ & \\
\hline \multicolumn{4}{|l|}{ Biguanide } \\
\hline Metformin (A10BA02) & $32(41.5)$ & $47(38.84)$ & 0.8169 \\
\hline \multicolumn{4}{|l|}{ Sulfonylureas } \\
\hline Glibenclamide (A10BB01) & $2(2.59)$ & $3(2.48)$ & 1.0000 \\
\hline Gliclazide (A10BB09) & $5(6.49)$ & $10(8.27)$ & 0.7853 \\
\hline Glimepiride (A10BB12) & $5(6.49)$ & $3(2.48)$ & 0.2712 \\
\hline \multicolumn{4}{|l|}{ Alpha-glucosidase inhibitors } \\
\hline Acarbose (A10BH02) & $1(1.30)$ & $0(0)$ & 0.4010 \\
\hline \multicolumn{4}{|l|}{ Gliptin } \\
\hline Vildagliptin (A10BH02) & $1(1.30)$ & $4(3.30)$ & 0.6501 \\
\hline \multicolumn{4}{|l|}{ Insulins } \\
\hline Human NPH (A10AC01) & $25(32.47)$ & $36(29.75)$ & 0.9901 \\
\hline Human Regular (R) (A10AB01) & $6(7.80)$ & $18(14.88)$ & 0.1658 \\
\hline TOTAL & $77(100)$ & $121(100)$ & \\
\hline Monotherapy & n (\%) & n (\%) & \\
\hline Metformin (M) & $14(32.60)$ & $5(8.77)$ & $* * 0.0041$ \\
\hline NPH Insulin (NPH) & $8(18.60)$ & $3(5.23)$ & 0.0515 \\
\hline Subtotal & $22(51.2)$ & $8(14.0)$ & $* * 0.0002$ \\
\hline Association of two antidiabetic drugs & n $(\%)$ & n (\%) & \\
\hline M + Sulfonylureas (S) & $3(6.98)$ & $12(21.05)$ & 0.0873 \\
\hline $\mathrm{M}+\mathrm{NPH}$ & $9(20.93)$ & $12(21.05)$ & 0.8157 \\
\hline$M+$ Vildagliptin & 0 & $4(6.67)$ & 0.1320 \\
\hline $\mathrm{NPH}+\mathrm{R}$ Insulin & $2(4.65)$ & $6(10.53)$ & 0.4604 \\
\hline $\mathrm{NPH}+\mathrm{S}$ & $1(2.33)$ & $0(0)$ & 0.4300 \\
\hline Subtotal & $15(34.9)$ & $34(59.6)$ & $* * 0.0244$ \\
\hline \multicolumn{4}{|l|}{ Association of three antidiabetic drugs } \\
\hline $\mathrm{M}+\mathrm{NPH}+\mathrm{R}$ Insulin & $4(9.30)$ & $11(19.29)$ & 0.2579 \\
\hline $\mathrm{M}+\mathrm{S}+\mathrm{NPH}$ & $1(2.33)$ & $3(5.26)$ & 0.6325 \\
\hline $\mathrm{M}+$ Vildagliptin + Acarbose & $1(2.33)$ & $0(0)$ & 0.4300 \\
\hline $\mathrm{NPH}+\mathrm{S}+\mathrm{R}$ Insulin & 0 & $1(1.75)$ & 1.0000 \\
\hline Subtotal & $6(13.9)$ & $15(26.4)$ & 0.2096 \\
\hline TOTAL & $43(100)$ & $57(100)$ & \\
\hline
\end{tabular}

ATC - Anatomical Therapeutic Chemical. SD - standard deviation. *Statistically significant difference (Student's $t$-test, $P \leq 0.05$ ). **Statistically significant difference (Chi-square test, $\mathrm{p} \leq 0.05$ ).

associated with poor glycemic control and antidiabetic drugrelated negative outcomes may contribute toward improving actions that favor glycemic control in these patients.
In the present study, unsatisfactory glycemic control in type 2 diabetes mellitus patients was associated with age group ( $<65$ years), family history of diabetes, 
TABLE III - Antidiabetic drug-related negative outcomes according to glycemic control

\begin{tabular}{|c|c|c|c|}
\hline DNO Categories/Subcategories & $\begin{array}{c}\text { Satisfactory } \\
\text { n (\%) }\end{array}$ & $\begin{array}{c}\text { Unsatisfactory } \\
\text { n (\%) } \\
\end{array}$ & p-value \\
\hline \multicolumn{4}{|l|}{ Inefficacy } \\
\hline \multicolumn{4}{|l|}{ Non-quantitative inefficacy } \\
\hline DRP: non-compliance with daily dose & $0(0)$ & $16(16.34)$ & 0.1217 \\
\hline DRP: Drug Interaction & $0(0)$ & $13(13.26)$ & 0.2088 \\
\hline \multicolumn{4}{|l|}{ Quantitative inefficacy } \\
\hline DRP: non-compliance with daily dose & $0(0)$ & $33(33.68)$ & $* 0.0030$ \\
\hline Subtotal & $\mathbf{0}(\mathbf{0})$ & $62(63.3)$ & $*<0.0001$ \\
\hline \multicolumn{4}{|l|}{ Safety } \\
\hline \multicolumn{4}{|l|}{ Non-quantitative safety } \\
\hline DRP: Adverse effect & $8(50.00)$ & $14(14.28)$ & 0.8102 \\
\hline DRP: Drug interaction & $5(31.25)$ & $13(13.26)$ & 0.1135 \\
\hline \multicolumn{4}{|l|}{ Quantitative safety } \\
\hline DRP: Adverse effect & $2(12.50)$ & $5(5.10)$ & 1.000 \\
\hline DRP: Precautions in use & $1(6.25)$ & $4(4.08)$ & 0.6712 \\
\hline Subtotal & $16(0)$ & $36(36.7)$ & $*<0.0001$ \\
\hline Total $(n=114)$ & $16(100)$ & $98(100)$ & \\
\hline
\end{tabular}

DNO - Antidiabetic drug-related negative outcomes. DRP - Drug-related problems. *Statistically significant difference (Fisher's exact test, $\mathrm{p} \leq 0.05$ ).

presence of therapy associated with diabetes treatment, and antidiabetic drug-related negative outcomes.

Although age is considered a predictive factor in the prevalence of type 2 diabetes mellitus (Brazilian Society of Diabetes, 2014), the results of this study were similar for both adult and elderly groups and mirrored findings of Zaman and Fun (2013). Cramer (2004) observed that 73\% of adult participants (mean age 50 years) had unsatisfactory glycemic control, similar to the rate found in the present study, in which $71 \%$ of adults had poor disease control.

According to the Brazilian Diabetes Association (2014), diabetes death rates (per 100 thousand persons) rise with age from 0.5 ( 0 -18 years) to 213.4 ( $\geq 60$ years) where these results could be partially explained by the prevalence of adults with uncontrolled disease.

Some authors report that the following factors may limit glycemic control in type 2 diabetes mellitus patients: economic status, cognitive function impairment, comorbidities (Thompson et al., 2014), overweight/ obesity, disease diagnosed for long period (Ewenighi et al., 2013), lower adherence to drug treatment (Cramer, 2004; Voorham et al., 2011; Ross, 2013), polypharmacy, adverse effects, use of injectable antidiabetic agents (Ross, 2013; Thompson et al., 2014) and risk of hypoglycemia (Thompson et al., 2014).
Among these factors, economic status, disease diagnosed for long period, obesity, comorbidities, hypoglycemic crises, polypharmacy, and the use of insulins as the main injectable antidiabetic agents were evaluated in the present study, but were not associated with the lack of control of diabetes in the population studied. The proportion of patients with an elevated number of comorbidities and hypoglycemic crises was very similar between the groups. Other variables associated with patients' unsatisfactory glycemic control were use of antidiabetic agents in combined therapy and their negative drug outcomes.

Metformin and NPH insulin were the most commonly prescribed drugs, and monotherapy with metformin was more indicated for patients with satisfactory glycemic control (around 33\% of prescriptions). In the present study, the patients that used two or more drugs for diabetes had a higher risk of not attaining the desirable glycemic levels for disease control. Adherence to treatment for type 2 diabetes mellitus is one of the major obstacles to achieving the expected benefits of this pharmacotherapy (Donnan et al., 2002; Sunya-Lee et al., 2014).

Regarding treatment regimens, the most prescribed for the group of patients with satisfactory glycemic control was metformin combined with NPH insulin, while 
TABLE IV - Characterization of drug interactions and precautions in use associated with drug-related outcomes according to glycemic control

\begin{tabular}{|c|c|c|c|c|c|}
\hline Antidiabetic agents & Other drugs & $\begin{array}{l}\text { Effects of } \\
\text { interaction }\end{array}$ & $\begin{array}{c}\text { Satisfactory } \\
\text { n (\%) }\end{array}$ & $\begin{array}{c}\text { Unsatisfactory } \\
\text { n (\%) }\end{array}$ & p-value \\
\hline \multicolumn{6}{|c|}{ Non-quantitative ineffectiveness } \\
\hline $\mathrm{R}$ and/or NPH & Levothyroxine & $\begin{array}{c}\text { Risk of } \\
\text { hypoglycemia }\end{array}$ & $0(0)$ & $8(61.53)$ & 1.000 \\
\hline \multirow[t]{2}{*}{$\mathrm{R}$ and/or NPH and/or metformin } & $\begin{array}{l}\text { Atenolol or } \\
\text { propranolol }\end{array}$ & $\begin{array}{c}\text { Risk of } \\
\text { hypoglycemia }\end{array}$ & $0(0)$ & $5(38.46)$ & 1.000 \\
\hline & & Total & $\mathbf{0}(\mathbf{0})$ & $13(100)$ & \\
\hline \multicolumn{6}{|c|}{ Non-quantitative safety } \\
\hline $\mathrm{R}$ and/or $\mathrm{NPH}$ & $\begin{array}{l}\text { Losartan or } \\
\text { acetylsalicylic } \\
\text { acid }\end{array}$ & $\begin{array}{c}\text { Risk of } \\
\text { hypoglycemia }\end{array}$ & $5(100)$ & $12(92.30)$ & 1.000 \\
\hline \multirow[t]{2}{*}{ Metformin } & Digoxin & $\begin{array}{l}\text { Risk of increased } \\
\text { metformin plasma } \\
\text { concentration }\end{array}$ & $0(0)$ & $1(7.70)$ & 1.000 \\
\hline & & Total & $5(100)$ & $13(100)$ & \\
\hline \multicolumn{6}{|c|}{ Quantitative safety } \\
\hline Drug & $\begin{array}{c}\text { Clinical } \\
\text { condition }\end{array}$ & $\begin{array}{l}\text { Precaution in } \\
\text { use (reasons) }\end{array}$ & & & \\
\hline $\mathrm{R}$ and/or NPH & $\begin{array}{l}\text { Renal failure or } \\
\text { thyroid disease }\end{array}$ & $\begin{array}{c}\text { Risk of } \\
\text { hypoglycemia }\end{array}$ & $1(100)$ & $4(100)$ & 1.000 \\
\hline
\end{tabular}

$\mathrm{R}$ and/or NPH - Regular and/or NPH Insulin. No statistically significant difference (Fisher's Exact test, $\mathrm{p}>0.05$ ).

TABLE V - Characterization of adverse drug reactions according to glycemic control

\begin{tabular}{|c|c|c|c|c|c|}
\hline Drugs & Adverse effect description & Causality/Severity & $\begin{array}{l}\text { Satisfactory } \\
\text { n (\%) }\end{array}$ & $\begin{array}{c}\text { Unsatisfactory } \\
\text { n (\%) }\end{array}$ & p-value \\
\hline Metformin & $\begin{array}{l}\text { Nausea, heartburn, diarrhea } \\
\text { or abdominal pain }\end{array}$ & $\begin{array}{l}\text { Definite or probable/mild } \\
\text { or moderate }\end{array}$ & $10(100)$ & $17(89.47)$ & 0.5320 \\
\hline \multirow[t]{2}{*}{$\mathrm{R}$ and/or NPH } & Hypoglycemia crisis & Probable/moderate & 0 & $2(10.53)$ & 0.4865 \\
\hline & & Total & $10(100)$ & $19(100)$ & \\
\hline
\end{tabular}

$\mathrm{R}$ and/or NPH - Regular and/or NPH Insulin. No statistically significant difference (Fisher's Exact test, $\mathrm{p}>0.05$ ).

in the unsatisfactory control group, the most common combinations were metformin and sulfonylureas and metformin with NPH insulin. The combination of two antidiabetic agents was predominant in this group, and there were a higher number of patients using up to three such agents. According to Brazilian Diabetes Association guidelines (2014), glycemic control must be achieved not only with the use of drugs, but also through lifestyle change, which includes improving eating patterns and physical activity. These factors were not investigated in the present study, but could help to explain the results found. Jarab et al. (2014) and Chung et al. (2014) underscored the importance of disease management as a predictive factor for its control.

According to Holman et al. (2009b), when glycemic control is not achieved with the use of oral antidiabetic agents, insulin may be added in order to intensify the therapeutic regimen since this - combination has been shown to be effective in reaching safe glycemic targets. The addition of insulin to the therapeutic regimen is necessary to maintain glycemic level stability in the long run (Valerón, Pablos-Velasco, 2013).

Brazilian guidelines recommend the use of oral antidiabetic agents and insulin for type 2 diabetes mellitus 
treatment in monotherapy or combined therapy and in regimens established according to the disease history and patient's clinical characteristics: HbAlc, fasting and postprandial glucose levels; current comorbidities; and reinforce that treatment must be individualized according to the patient's characteristics (Brazilian Society of Diabetes, 2014).

Metformin was the most commonly used oral antidiabetic agent in monotherapy in patients with adequate glycemic control. This result corroborates the Brazilian and American guideline recommendations and the systematic review of Saenz et al. (2005), which reinforce the use of this drug as the first pharmacological option for type 2 diabetes mellitus monotherapy due to the superior results obtained in glycemic control for overweight or obese patients as well as the fact that it prevents vascular complications specific to diabetes and reduces mortality.

Forty-nine percent of the patients in the present study had DNO. Zaman and Fun (2013) found that $90 \%$ of diabetic patients in the hospital had DRP. Gastelurrutia et al. (2011) observed DRP in $80 \%$ of patients suffering from heart failure seen in a medical clinic. These disparities may be attributed to the different populations studied and to the patient inclusion criteria, since in the present study patients were included regardless of specific criteria that required special pharmaceutical care.

All patients were undergoing diabetic treatment and therefore had no negative outcomes related to untreated health problems. This is explained by the fact that the group of patients studied rigorously returned to the clinic every two to three months for a medical appointment. No problems were observed related to the unnecessary use of antidiabetic agents. The main problem observed in the unsatisfactory control group was the drug's nonquantitative ineffectiveness related to non-compliance with the frequency and/or the daily dose and to drug interactions that mainly occurred with the association of insulin with beta-blockers and levothyroxine, with the risk of reduced efficacy of these hypoglycemic agents.

In the present study, insulins were the main antidiabetic agents associated with drug interactions with the potential risk of generating negative outcomes due to ineffectiveness and safety. Drug interactions and precautions in use were mainly associated with the risk of hypoglycemic crisis. Metformin was associated with a higher number of adverse effects; one-third of adverse effects cases were due to the use of oral antidiabetic agents and insulin and more commonly hypoglycemia. Another study observed the main DRP for diabetes treatment: lack of knowledge regarding health problems, dosage problems, choice of drugs and drug interactions (Zaman, Fun, 2013).
The main problem related to the safety of antidiabetic agents in both groups was adverse effects, mainly due to the use of metformin associated with gastrointestinal symptoms. All of these effects were definite or probable and from mild to moderate, and no severe adverse effects were observed. Studies report that gastrointestinal discomfort is the most important metformin adverse effect (Valerón, Pablos-Velasco, 2013) and a strong relationship between polypharmacy and the presence of adverse effects was confirmed (Von Rozendaal, Krass, 2009; Gandhi et al., 2003; Braund et al., 2004; Onder et al., 2010). In the present study, most patients were in use of combined therapy.

Considering that this is a cross-sectional study, it was not possible to collect data that allowed the evaluation of pharmaceutical intervention effects. All patients were invited to participate in the pharmacotherapy followup and around $15 \%$ accepted. Most of the patients demonstrated difficulty of displacement mainly due to old age and access to transport, since they live in cities near Sorocaba. Therefore, patients were oriented regarding pharmacotherapy and/or pharmacology during the interview and possibly, when they returned to the facility, while some of the interventions were made by contact from the doctors in the sector.

The pharmaceutical interview conducted using a systematic method of data collection for antidiabetic agents enabled the identification of their negative outcomes. These outcomes pose a threat to health, especially among adults with heart disease and/or diabetes mellitus (Al Hamid et al., 2014). Thus, the investigation and identification of DNOs may improve patient care regarding treatment.

\section{CONCLUSIONS}

In the present study, the factors associated with poor glycemic control in patients with type 2 diabetes mellitus were identified. Therefore, adults, individuals with a family history of diabetes, in use of two or more antidiabetic agents, and those exhibiting negative outcomes associated with the use of these drugs must be prioritized with regard to planning of interventions that favor disease control. The pharmaceutical interview also allowed identification of antidiabetic drug-related negative clinical outcomes and enabled the pharmacotherapy follow-up of some patients. Characterization of patient profile and aspects associated with drug treatment may contribute to the planning of interventions that improve patient care. 


\section{ACKNOWLEDGMENTS}

We would like to extend our thanks to the FAPESP and CAPES for the financial support.

\section{REFERENCES}

ALHAMID, A.; GHALEB, M.; ALJADHEY, H.;ASLANPOUR, Z. A systematic review of qualitative research on the contributory factors leading to medicine-related problems from the perspectives of adult patients with cardiovascular diseases and diabetes mellitus. BMJ Open, v.4, p.e005992, 2014.

AMARILES, P.; SABATER-HERNÁNDEZ, D.; GARCÍAJIMÉNEZ, E.; RODRÍGUEZ-CHAMORRO, M.A.; PRATS-MÁS, R.; MARÍN-MAGÁN, F.; GALÁNCEBALLOS, J.A.; JIMÉNEZ-MARTÍN, J.; FAUS, M.J. Effectiveness of dader method for pharmaceutical care on control of blood pressure and total cholesterol in outpatients with cardiovascular disease or cardiovascular risk: emdader-cv randomized controlled trial. J. Manag. Care Pharm., v.18, p.311-23, 2012.

ALMEIDA-PITITTO, B., DIAS, M.L.; DE MORAES, A.C.; FERREIRA, S.R.; FRANCO, D.R.; ELIASCHEWITZ, F.G. Type 2 diabetes in Brazil: epidemiology and management. Diab. Metab. Syndr. Obes., v.8, p.17-28, 2015.

AMERICAN DIABETES ASSOCIATION. ADA. Diabetes basics: statistics about diabetes. Alexandria; 2014. Available at: <http://www.diabetes.org/diabetes-basics/statistics $>$. Access on: 02 Nov. 2014.

BRAUND, R.; COULTER, C.V.; BODINGTON, A.J.; GILES, L.M.; GREIG, A.M.; HEASLIP, L.J.; MARSHALL, B.J. Drug related problems identified by community pharmacists on hospital discharge prescriptions in New Zealand. Int. J. Clin. Pharm., v.36, p.498-502, 2014.

BRAZILIAN SOCIETY OF DIABETES. BSD. Guidelines of the Brazilian society of Diabetes: 2013-2014. São Paulo: AC Farmacêutica, 2014.

COMMITTEE DE CONSENSO. Third Consensus of Granada on drug-related problems (DRPs) and negative outcomes associated with medication (MRI). Ars Pharm., v.48, p.517, 2007.
CORRER, C.J.; MELCHIORS, A.C.; FERNANDEZ-ILIMOS, F.; PONTAROLO, R. Effects of a pharmacotherapy followup in community pharmacies on type 2 diabetes patients in Brazil. Int. J. Clin. Pharm., v.33, p.273-280, 2011.

CHUNG, W.W.; CHUA, S.S.; LAI, P.S.; CHAN S.P. Effects of a pharmaceutical care model on medication adherence and glycemic control of people with type 2 diabetes. Patient Prefer. Adher, v.8, p.1185-1194, 2014.

CRAMER, J. A. A systematic review of adherence with medications for diabetes. Diab. Care, v.27, p.1218-1224, 2004.

DONNAN, P. T.; MACDONALD, T. M.; MORRIS, A. D. Adherence to prescribed oral hypoglycemic medication in a population of patients with Type 2 diabetes: a retrospective cohort study. Diab. Med., v.19, p.279-284, 2002.

DUCKWORTH, W.; ABRAIRA, C.; MORITZ, T.; REDA, D.; EMANUELE, N.; REAVEN, P.D.; ZIEVE, F.J.; MARKS, J.; DAVIS, S.N.; HAYWARD, R.; WARREN, S.R.; GOLDMAN, S.; MCCARREN, M.; VITEK, M.E.; HENDERSON, W.G.; HUANG, G.D. Glucose control and vascular complications in veterans with type 2 diabetes. $N$. Engl. J. Med., v.360, p.129-139, 2009.

EDWARDS, I.R.; ARONSON, J.K. Adverse drug reactions: definitions, diagnosis, and management. Lancet, v.356, p.1255-1259, 2000.

EWENIGHI, C.O.; UCHECHUKWU, D.; ADEJUMO, B.I.; ONYEANUSI, J.C.; NNATUANYA, I.N.; ONOH, O.G.; OKORIE, C.E.; OGBUIKE, O.I. Responses to glycemic control therapy according to age, gender, level of adiposity, and duration of diabetes in type 2 diabetic patients. Indian J. Med. Sci., v.67, p.61-69, 2013.

GANDHI, T.K; WEINGART, S.N.; BORUS, J.; SEGER, A.C.; PETERSON, J.; BURDICK, E.; SEGER, D.L.; SHU, K.; FEDERICO, F.; LEAPE, L.L.; BATES, D.W. Adverse drug events in ambulatory care. N. Engl. J. Med., v.348, p.15561564, 2003.

GROBER, E.; HALL, C.B.; HAHN, S.R.; LIPTON, R.B. Memory Impairment and Executive Dysfunction are Associated with Inadequately Controlled Diabetes in Older Adults. J. Prim. Care Comm. Health, v.2; p.229-233, 2011. 
GASTELURRUTIA, P.; BENRIMOJ, S.I.; ESPEJO, J.; TUNEU, L.; MANGUES, M. A.; BAYES-GENIS, A. Negative clinical outcomes associated with drug-related problems in heart failure (HF) outpatients: impact of a pharmacist in a multidisciplinary HF clinic. J. Cardiac. Fail, v.17, p.217-223, 2011.

HOLMAN, R.R.; SOURIJ, H.; CALIFF, R.M. Cardiovascular outcome trials of glucose-lowering drugs or strategies in type 2 diabetes. Lancet, v.383, p.2008-2017, 2014.

JARAB, A.S.; ALMRAYAT, R.; ALQUDAH, S.; THEHAIRAT, E.; MUKATTASH, T.L.; KHDOUR, M.; PINTO, S. Predictors of non-adherence to pharmacotherapy in patients with type 2 diabetes. Int. J. Clin. Pharm., v.36, p.725-733, 2014.

KLASCO, R.K. (Ed.). DRUGDEX System [Database on the Internet].Greenwood Village (Colorado): Thomson Micromedex; 1974-2010. Available at: $<$ http://www.micromedexsolutions.com/micromedex2/ librarian?partner=true $>$. Accessed on: 01 Dec. 2014.

NARANJO, C.A.; BUSTO, U.; SELLERS, E.M.; SANDOR, P.; RUIZ, I.; ROBERTS, E.A.; JANECEK, E.; DOMECQ, C.; GREENBLATT, D.J. A method for estimating the probability of adverse drug reactions. Clin. Pharmacol. Ther., v.30, p.239-245, 1981.

NATHAN, D.M; BUSE, J.B.; DAVIDSON, M.B.; FERRANNINI, E.; HOLMAN, R.R.; SHERWIN, R.; ZINMAN, B. Medical management of hyperglycemia in type 2 diabetes: a consensus algorithm for the initiation and adjustment of therapy: a consensus statement of the American Diabetes Association and the European Association for the Study of Diabetes. Diab. Care, v.32, p.93-203, 2009.

NOIA, A.S.; SECOLI, S.R.; DUARTE, Y.A.; LEBRÃO, M.L.; LIEBER, N.S. Factors associated to the use of psychotropic drugs by community-dwelling elderly in São Paulo city. Rev. Esc. Enferm., v.46, p.38-43, 2012.

ONDER, G.; PETROVIC, M.; TANGIISURAN, B.; MEINARDI, M.C.; MARKITO-NOTENBOOM, W.P.; SOMERS, A.; RAJKUMAR, C.; BERNABEI, R.; VAN DER CAMMEN, T.J. Development and validation of a score to assess risk of adverse drug reactions among inhospital patients 65 years or older: the gerontonet adr risk score. Arch. Intern. Med., v.170, p.1142-48, 2010.
ROSS, S.A. Breaking down patient and physician barriers to optimize glycemic control in type 2 diabetes. Am. J. Med., v.126, p.S38-48, 2013.

SAENZ, A.; FERNANDEZ-ESTEBAN, I.; MATAIX, A., AUSEJO, M.; ROQUE, M.; MOHER, D. Metformin monotherapy for type 2 diabetes mellitus. Cochr. Datab. Syst. Rev., v.20, p.CD002966, 2005.

SUNYA-LEE A.; DAWID P.; TIM M.; MICHAELA E. The adherence of type 2 diabetes mellitus patients with pharmacy care: a systematic review of randomized controlled trials. BMC Endocr Disord, v.14, p.53, 2014.

TAKAHASHI, P.S.K; SOUSA, A.B.; STORPIRTIS, S. Evaluation of negative outcomes associated with medication (NOM) by pharmacists at a home assistance programme in a Brazilian teaching hospital. Farm. Hosp., v.35, p.316e1316e10, 2011.

THOMPSON, A.M.; LINNEBUR, S.A.; VANDE GRIEND, J.P.; SASEEN, J.J. Glycemic targets and medication limitations for type 2 diabetes mellitus in the older adult. Consult. Pharm., v.29, p.110-123, 2014.

TRIMECHE, A.; BEN SLAMA, F.; BEN AMARA, H.; IBRAHIM, H.; DAHMOUNI, L.; DALY, N.; BEN MAMI, F. Multiple medication use in diabetic patients aged. Tunis Med., v.91, p.50-53, 2013.

VALERÓN, P. F.; PABLOS-VELASCO P. L. Limitations of insulin-dependents drugs in the treatment of tipe 2 diabetes mellitus. Med. Clin., v.141, p. 20-25, 2013.

V O OR H A M, J .; H A A I JER - R US K A M P, F.M .; WOLFFENBUTTEL, B.H.; STOLK, R.P.; DENIG, P. Groningen initiative to analyze type 2 diabetes treatment group. Medication adherence affects treatment modifications in patients with type 2 diabetes. Clin. Ther., v.33, p.121-134, 2011.

VAN ROOZENDAAL, B.W.; KRASS, I. Development of an evidence-based checklist for the detection of drug related problems in type 2 diabetes. Pharm. World Sci., v.31, p.580$595,2009$.

WALLIA, A.; MOLITCH, M.E. Insulin therapy for type 2 diabetes mellitus. JAMA, v.311, p.2315-2325, 2014. 
WHITING, D.R.; GUARIGUATA, L.; WEIL, C.; SHAW, J. IDF diabetes atlas: global estimates of the prevalence of diabetes for 2011 and 2030. Diab. Res. Clin. Pract., v.94: p. 311-321, 2011.

ZAMAN, H.H.; CHAI, L.L. Drug-related problems in type 2 diabetes mellitus patients with dyslipidemia. BMC Publ. Health, v.13, p.1192, 2013.
ZAMAN, H.H.; FUN, W.H. Drug related problems in type 2 diabetes patients with hypertension: a cross-sectional retrospective study. BMC Endocr. Disord., v.13, p.2, 2013.

Received for publication on $31^{\text {st }}$ December 2015 Accepted for publication on $10^{\text {th }}$ August 2016 